\title{
Erratum to: Willingness to Pay and Sensitivity to Time Framing: A Theoretical Analysis and an Application on Car Safety
}

\author{
Henrik Andersson • James K. Hammitt • \\ Gunnar Lindberg • Kristian Sundström
}

Published online: 19 October 2013

(C) Springer Science+Business Media Dordrecht 2013

\section{Erratum to: Environ Resource Econ DOI 10.1007/s10640-013-9644-0}

The authors would like to point out that the notation in the first parenthesis appearing on page 5 and last in the second paragraph should be $c$ with the subscript $\tau+T$, so the sentence reads 'This is reflected in our model by including a term $Z>0$ in the last time period, i.e. $u_{a}\left(c_{\tau+T}\right)=u_{a}(c)+Z$, where $Z$ represents the expected utility conditional on survival to $\tau+T$.'

The online version of the original article can be found under doi:10.1007/s10640-013-9644-0.

H. Andersson $(\varangle)$

Toulouse School of Economics (UT1C, CNRS, LERNA), 21 all.de Brienne,

31015 Toulouse Cedex 6, France

e-mail: henrik.andersson@tse-fr.eu

J. K. Hammitt

Center for Risk Analysis, Harvard University, Boston, MA, USA

J. K. Hammitt

Toulouse School of Economics (LERNA, INRA), Toulouse, France

G. Lindberg

Department of Transport Economics, VTI, Stockholm, Sweden

K. Sundström

AgriFood Economics Centre, Lund, Sweden 